\title{
Charge-Switchable Integrated Nanocatalysts for Substrate-Selective Degradation in Advanced Oxidation Processes
}

Guowu Zhan and Hua Chun Zeng*

NUS Graduate School for Integrative Sciences and Engineering, and Department of Chemical and Biomolecular Engineering, Faculty of Engineering, National University of Singapore, 10 Kent Ridge Crescent, Singapore 119260

*E-mail: chezhc@nus.edu.sg

\section{Table of Contents}

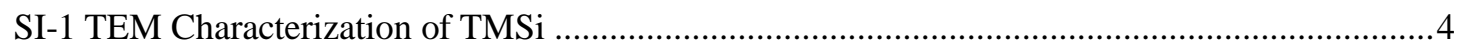

SI-2 EDX Characterization of TMSi Hollow Spheres .............................................................6

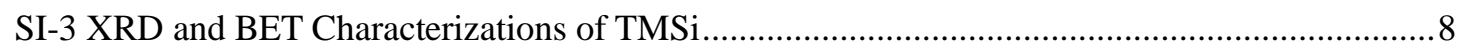

SI-4 TEM Characterization of TMSi@PDA ........................................................................... 9

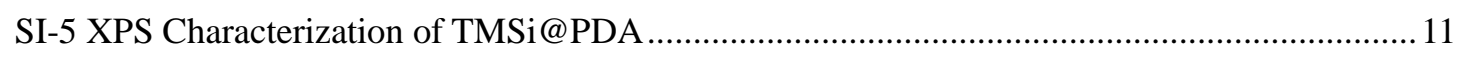

SI-6 Thermogravimetry Coupled with FTIR Characterization ....................................................... 12

SI-7 Characterization of Pt/TMSi (TM = Fe, Co, Ni) ....................................................... 13

SI-8 Characterization of Pt/MnSi@PDA with Different PDA Coating Thickness ........................ 14

SI-9 XPS Characterization of Pt/TMSi@PDA ........................................................................... 15

SI-10 Zeta-Potential of Pt/TMSi@PDA ...................................................................................... 16

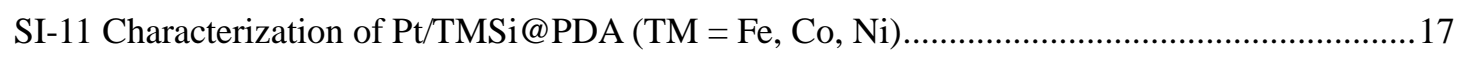

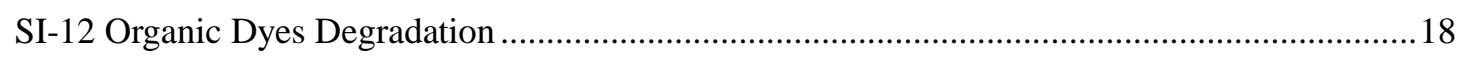

\section{Supplementary Figures}

Figure S1. TEM images (at different magnifications) of Mn silicate................................ 4

Figure S2. TEM images (at different magnifications) of Fe silicate. ................................. 4

Figure S3. TEM images (at different magnifications) of Co silicate....................................5

Figure S4. TEM images (at different magnifications) of Ni silicate.................................5

Figure S5. EDX spectra of Mn silicate hollow spheres. The $\mathrm{Cu}$ element signal originates 
from the sample holder (copper grid). Inset shows the elements ratios.

Figure S6. EDX spectra of Fe silicate hollow spheres. The $\mathrm{Cu}$ element signal originates from the sample holder (copper grid). Inset shows the elements ratios.

Figure S7. EDX spectra of Co silicate hollow spheres. The $\mathrm{Cu}$ element signal originates from the sample holder (copper grid). Inset shows the elements ratios.

Figure S8. EDX spectra of $\mathrm{Ni}$ silicate hollow spheres. The $\mathrm{Cu}$ element signal originates from the sample holder (copper grid). Inset shows the elements ratios.

Figure S9. (a) XRD patterns of the transition metal silicates, (b) $\mathrm{N}_{2}$ adsorption-desorption isotherms of the transition metal silicates, and (c-f) the corresponding pore size distribution curves analyzed by the Barrett-Joyner-Halenda $(\mathrm{BJH})$ method (from the adsorption branch of the isotherms).

Figure S10. Representative TEM images (at different magnifications) of FeSi@PDA...........9

Figure S11. Representative TEM images (at different magnifications) of CoSi@PDA. .........9

Figure S12. Representative TEM images (at different magnifications) of NiSi@PDA.........10

Figure S13. XPS spectrum with survey scan for MnSi@PDA sample. .................................11

Figure S14. Profiled 3D-FTIR spectra of the evolved gases during the thermogravimetry analysis (TGA) of MnSi@PDA sample.

Figure S15. TEM images (at different magnifications) of (a-c) Pt/NiSi, (d-f) Pt/CoSi, and (g-i) $\mathrm{Pt} / \mathrm{FeSi}$ samples.

Figure S16. TEM images, EDX elemental maps, and the corresponding EDX spectra of $(a, d)$ $\mathrm{Pt} / \mathrm{NiSi}$, (b,e) $\mathrm{Pt} / \mathrm{CoSi}$, and (d,f) Pt/FeSi. Only peaks belonging to transition metals and Pt were labeled in the EDX spectra. 13

Figure S17. (a-c) TEM images and (d) TGA scans (in air atmosphere, $50 \mathrm{~mL} / \mathrm{min}$ ) of Pt/MnSi@PDA samples with different thickness of PDA coating layer.........................14

Figure S18. XPS spectrum with survey scan for Pt/MnSi@PDA sample...............................15

Figure S19. High resolution Pt $4 f$ core-level XPS spectrum of Pt/MnSi@PDA sample.........15

Figure S20. Plot of the zeta-potential of Pt/MnSi@PDA samples measured as a function of $\mathrm{pH}$ value.

Figure S21. TEM images (at different magnifications) of (a-c) Pt/NiSi@PDA, (d-f) Pt/CoSi@PDA, and (g-i) Pt/FeSi@PDA. The mass ratio between Pt/TMSi and dopamine in the synthetic solution was set at $2: 1$ (20 mg to $10 \mathrm{mg})$.........................17

Figure S22. Molecular structures of organic dyes studied in this work. ...............................18

Figure S23. Degradation efficiency vs. time plots for five different dyes over Pt/MnSi@PDA catalyst at (a) $\mathrm{pH}$ of 10 , and (b) $\mathrm{pH}$ of 2. Data was obtained from the time dependence UV-vis spectra profiles shown in main text (Figure 10 and Figure 11) .18

Figure S24. UV-vis spectra of methyl orange (MO) in different $\mathrm{pH}$ conditions. ....................19

Figure S25. UV-vis spectra of Congo red (CR) in different $\mathrm{pH}$ conditions. ..........................19

Figure S26. UV-vis spectra of thymol blue (TB) in different $\mathrm{pH}$ conditions.........................20

Figure S27. UV-vis absorption spectra of thymol blue (TB) as a function of time during the advanced oxidation processes (AOP) by using Mn silicate as a catalyst at solution $\mathrm{pH}$ of 2 .

Figure S28. Degradation efficiency $v s$. time plots for MB over Pt/MnSi@PDA catalysts with different thickness of PDA coating layer (equal amount of Pt was used for different catalysts) .21 
Figure S29. (a-d) Representative TEM images (at different magnifications) of Pt/MnSi@ NC catalyst.

Figure S30. Degradation of $\mathrm{MO}$ in a control experiment by adding $5 \mathrm{~mL}$ of $\mathrm{H}_{2} \mathrm{O}_{2}$ in the absence of Pt/TMSi@PDA catalyst.

Figure S31. Catalyst stability of Pt/MnSi@PDA presented with degradation efficiency toward MB during five consecutive reactions (50 mg/L, $\mathrm{pH}$ of 10 , and time of $30 \mathrm{~min}$ ).

Figure S32. UV-vis absorption spectra of $\mathrm{MO} / \mathrm{MB}$ mixtures during the advanced oxidation processes (AOP) over three different catalysts. Conditions: solution $\mathrm{pH}$ of $10, \mathrm{MB}$ concentration of $50 \mathrm{mg} / \mathrm{L}$, and $\mathrm{MO}$ concentration of $25 \mathrm{mg} / \mathrm{L}$. The reactions finished at about $10 \mathrm{~min}$, and UV-vis absorption spectra of the solution at $10 \mathrm{~min}$ were quite similar to the ones at $30 \mathrm{~min}$. 


\section{SI-1 TEM Characterization of TMSi}

Four different kinds of spherical transition metal silicates (TMSi) were prepared in this works, including $\mathrm{Mn}, \mathrm{Fe}$, Co and Ni silicates. All these four TMSi own both hollow cavities and mesoporous shells, which are highly suitable as support materials for immobilization of noble metal nanoparticles (e.g., Pt).
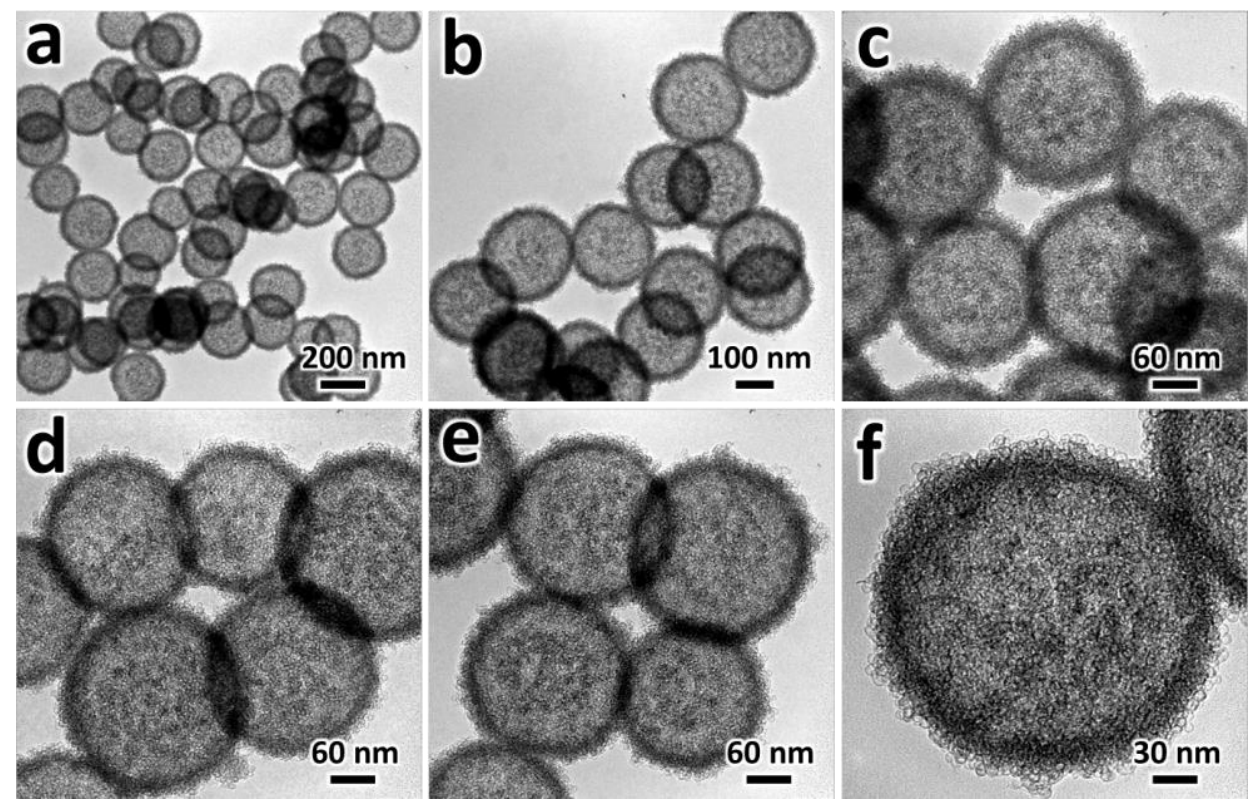

Figure S1. TEM images (at different magnifications) of Mn silicate.
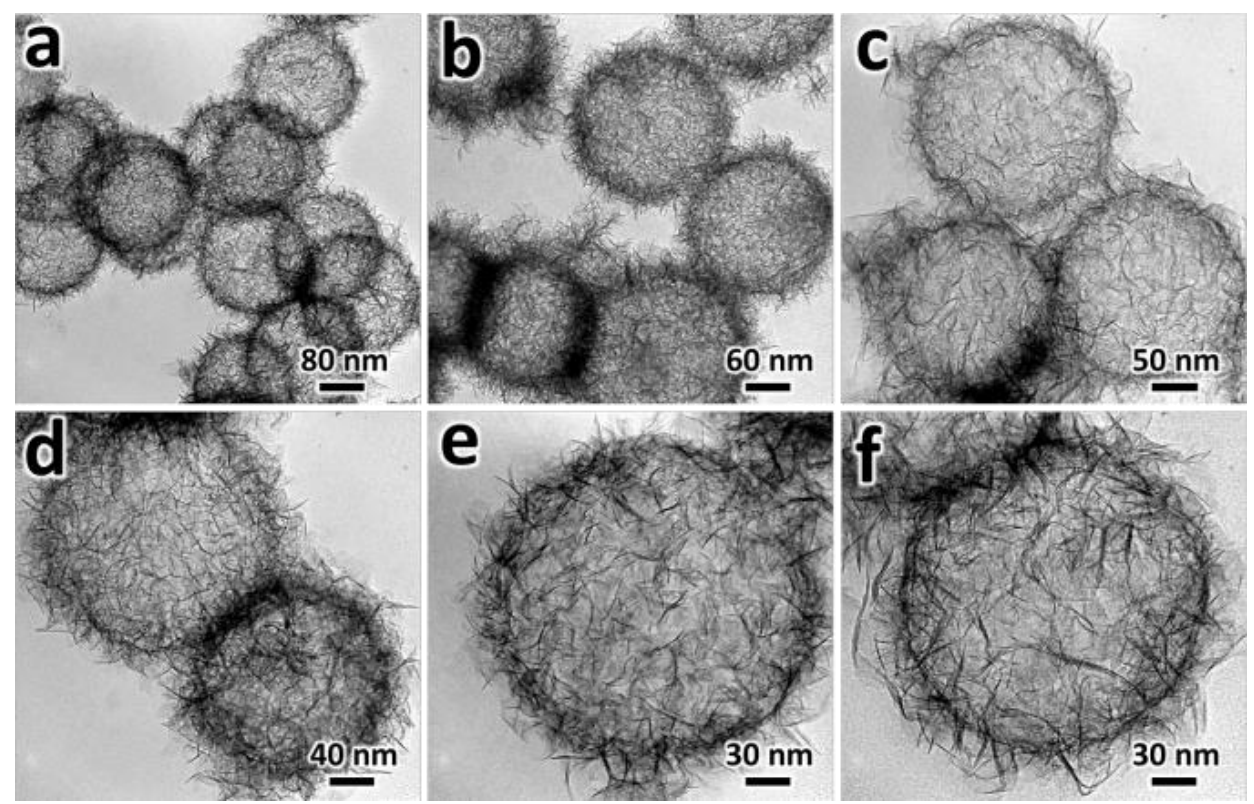

Figure S2. TEM images (at different magnifications) of Fe silicate. 

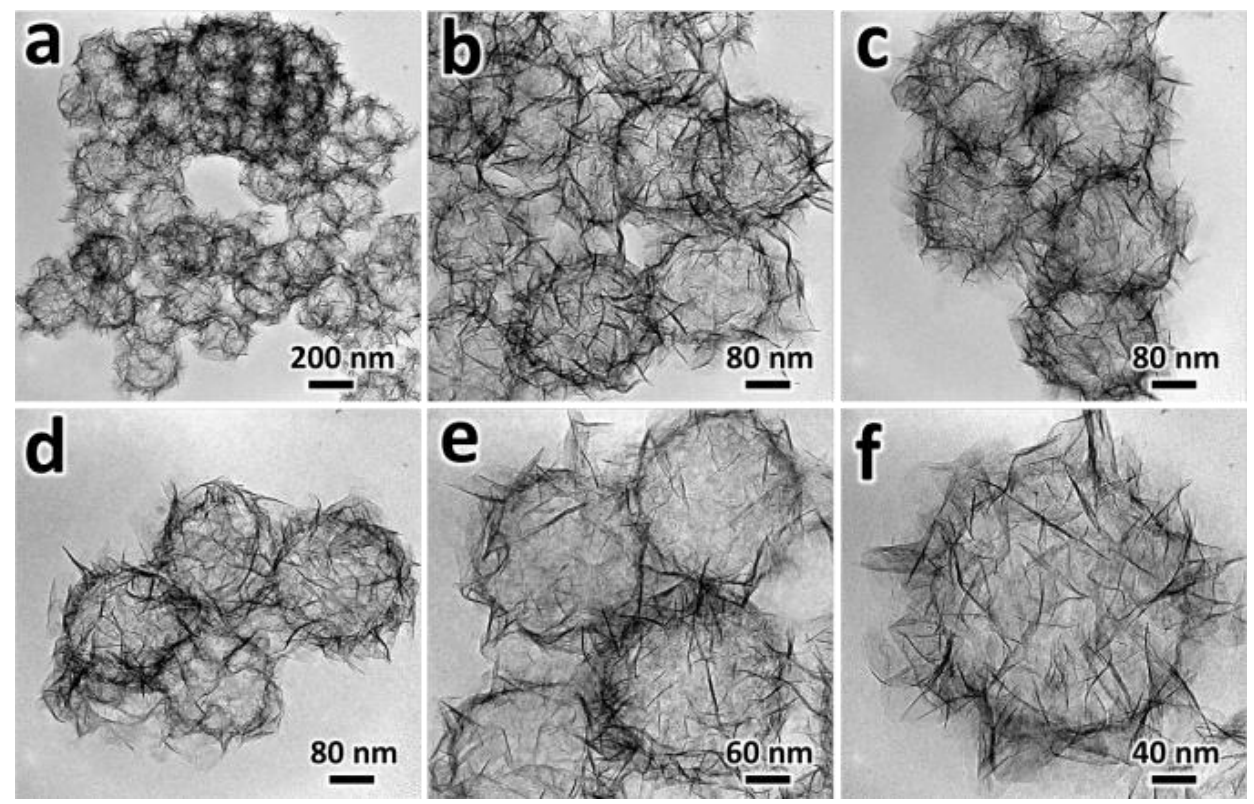

Figure S3. TEM images (at different magnifications) of Co silicate.
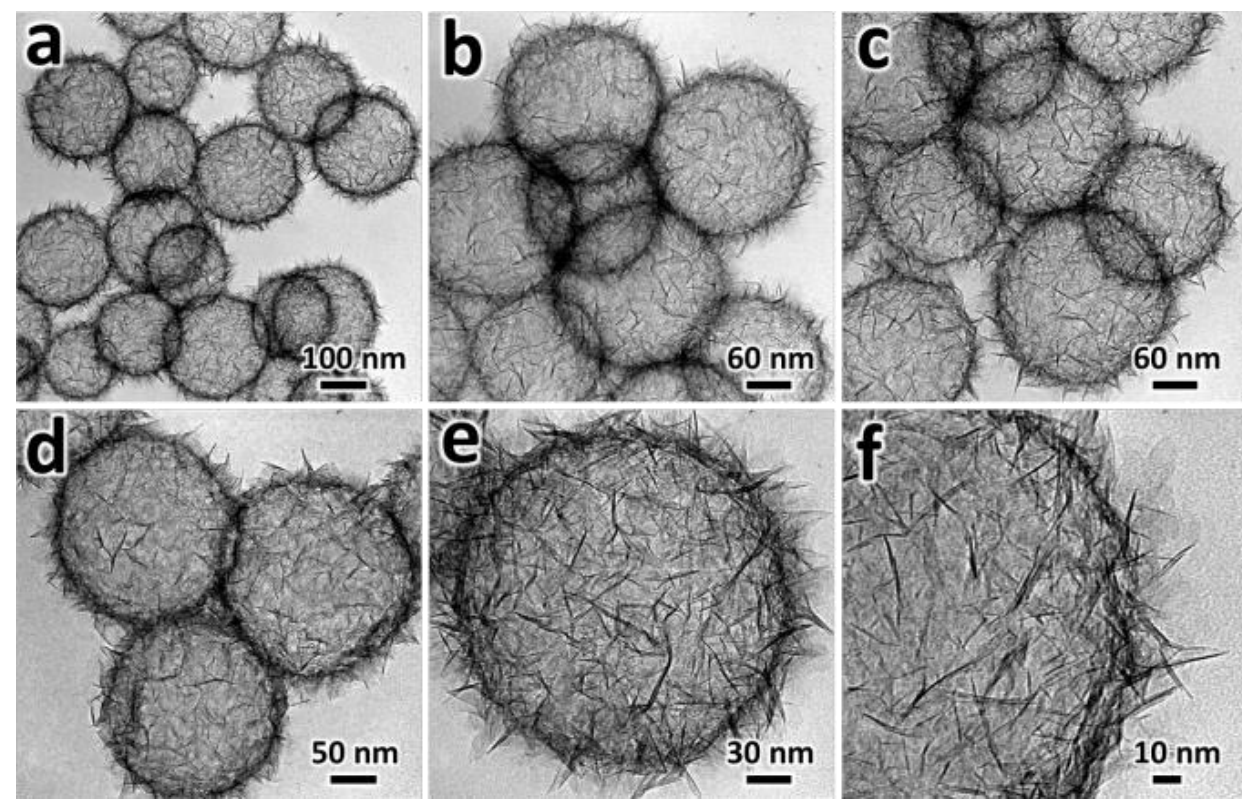

Figure S4. TEM images (at different magnifications) of Ni silicate. 


\section{SI-2 EDX Characterization of TMSi Hollow Spheres}

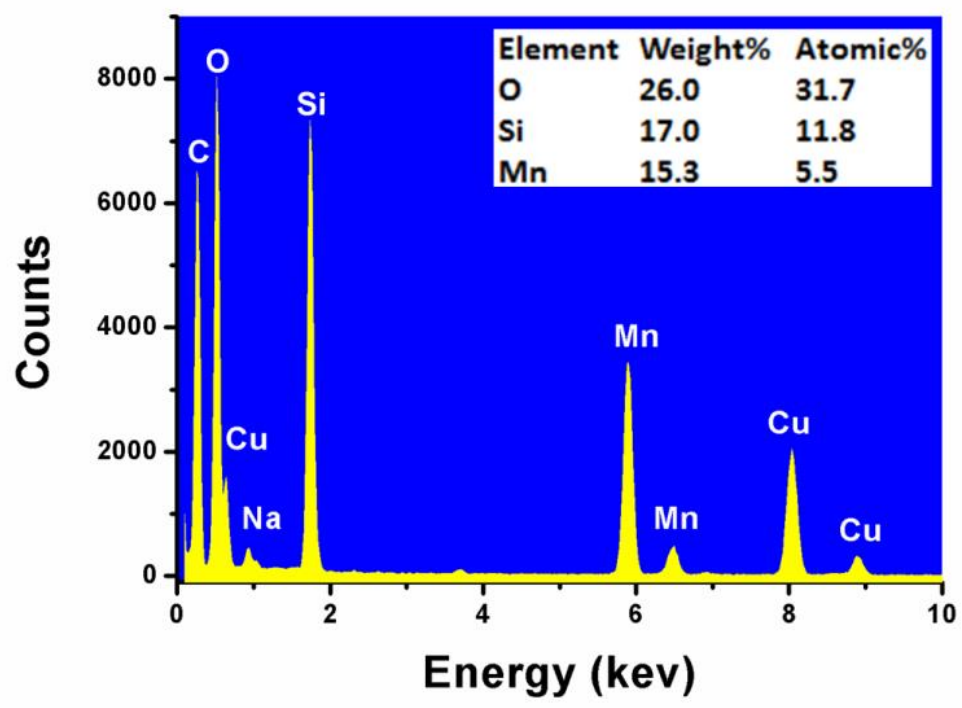

Figure S5. EDX spectra of Mn silicate hollow spheres. The $\mathrm{Cu}$ element signal originates from the sample holder (copper grid). Inset shows the elements ratios.

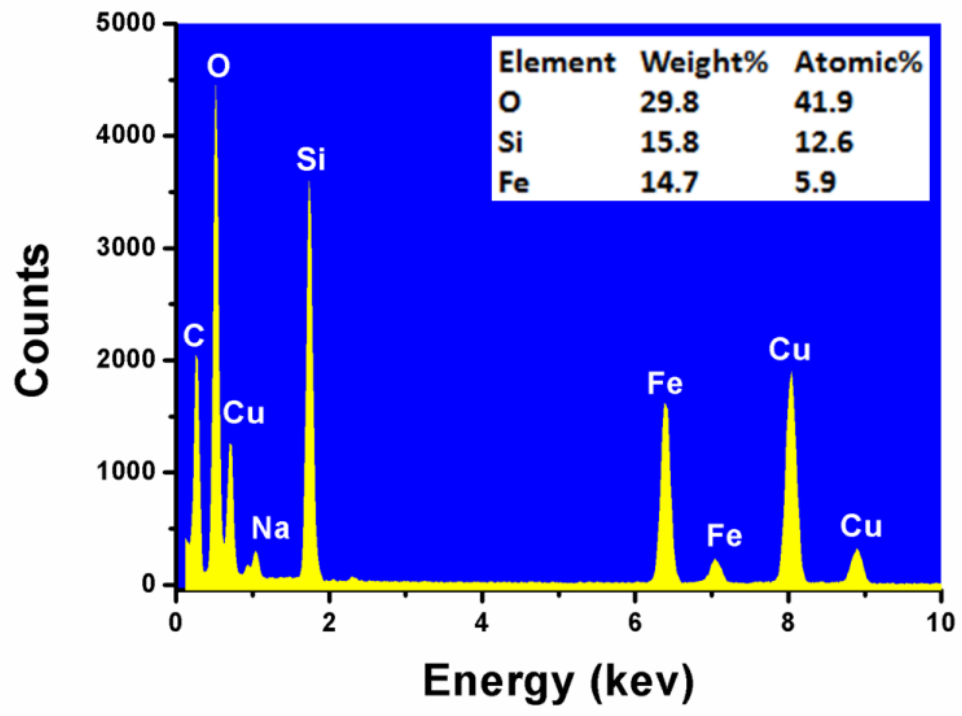

Figure S6. EDX spectra of $\mathrm{Fe}$ silicate hollow spheres. The $\mathrm{Cu}$ element signal originates from the sample holder (copper grid). Inset shows the elements ratios. 


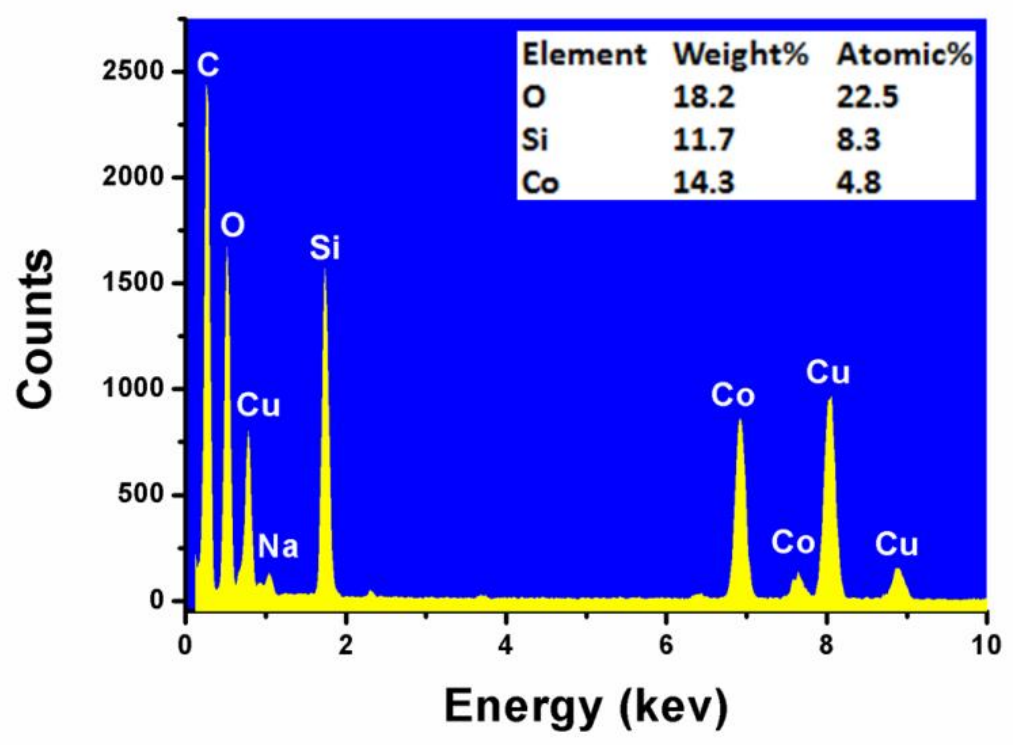

Figure S7. EDX spectra of Co silicate hollow spheres. The $\mathrm{Cu}$ element signal originates from the sample holder (copper grid). Inset shows the elements ratios.

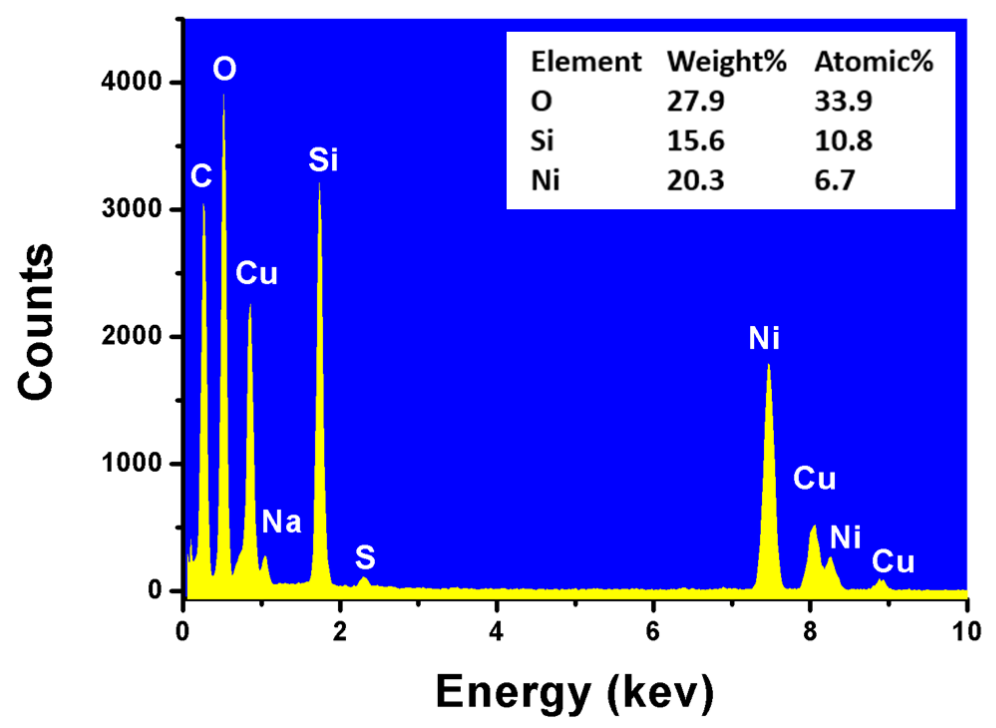

Figure S8. EDX spectra of $\mathrm{Ni}$ silicate hollow spheres. The $\mathrm{Cu}$ element signal originates from the sample holder (copper grid). Inset shows the elements ratios.

Comments: A trace amount of sulfur ( $\mathrm{S} / \mathrm{Ni}$ weight ratio $=0.02)$ was present due to the contamination of sulfate ions (precursor ions) in the product. 


\section{SI-3 XRD and BET Characterizations of TMSi}
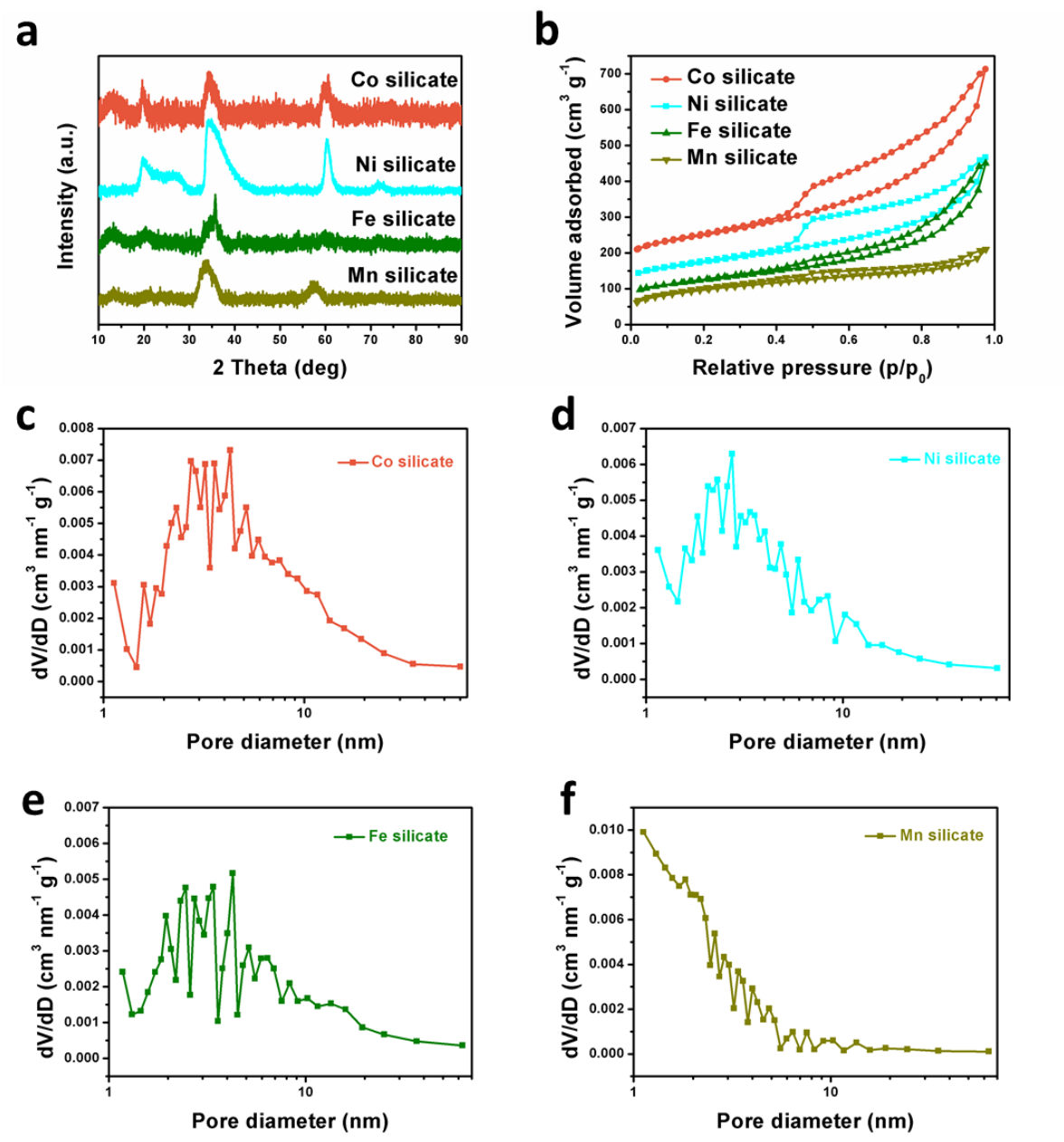

Figure S9. (a) XRD patterns of the transition metal silicates, (b) $\mathrm{N}_{2}$ adsorption-desorption isotherms of the transition metal silicates, and (c-f) the corresponding pore size distribution curves analyzed by the Barrett-Joyner-Halenda (BJH) method (from the adsorption branch of the isotherms).

Comments: We found that the tensile strength effect indeed exists in our $\mathrm{N}_{2}$ isotherms. ${ }^{1-3}$ As shown, the desorption branch of the isotherm shows a forced closure at $\mathrm{p} / \mathrm{p}_{0}$ ranged $0.44-0.50$ (due to a sudden drop in the volume adsorbed along the desorption branch). Therefore, the desorption branch of the isotherm is not able to determine the accurate pore size. For this reason, we calculated the pore size distribution based on the adsorption branch of the isotherms. As shown, there are a wide range of mesopores (from $2 \mathrm{~nm}$ to $10 \mathrm{~nm}$ ) existing in these transition metal silicates, which result from the inter-particle spaces of nanosheets or tiny nanospheres which are hollow. The micropores in the Mn silicate are most likely resulted from the shell of the tiny hollow spheres. 


\section{SI-4 TEM Characterization of TMSi@PDA}
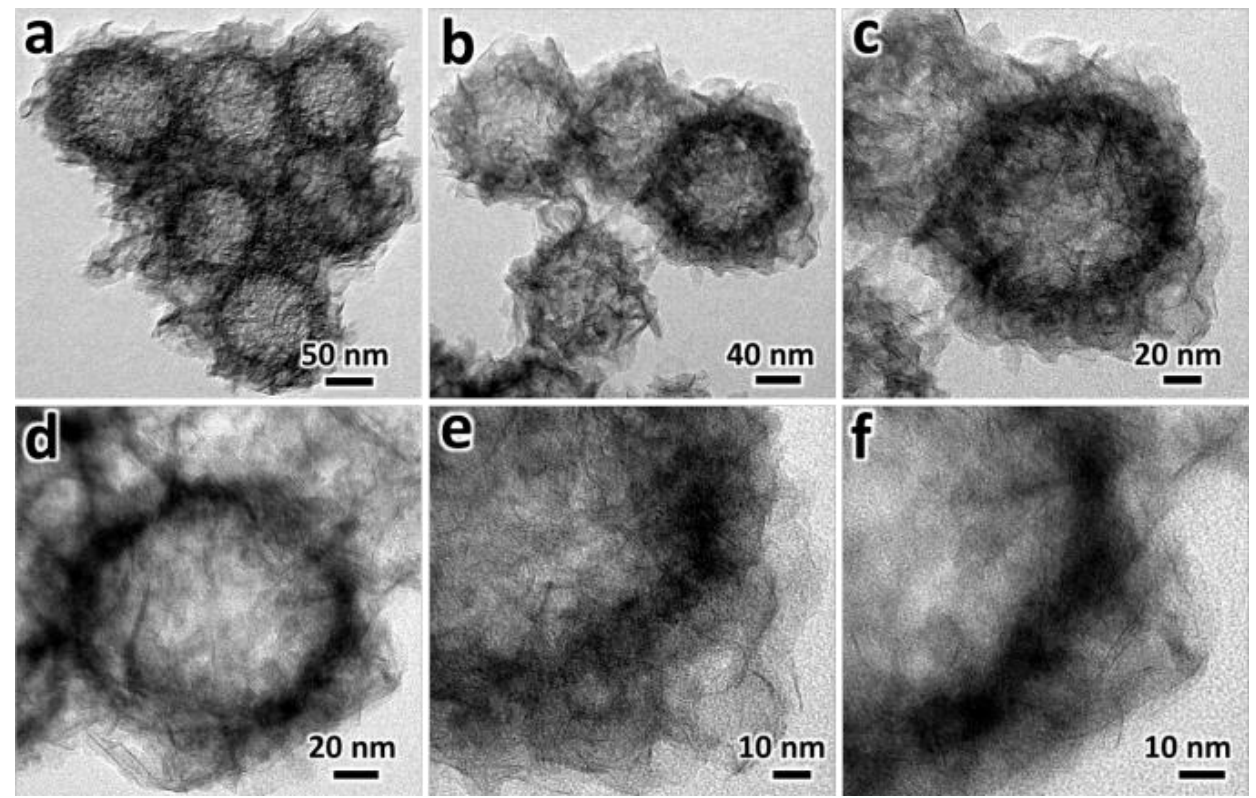

Figure S10. Representative TEM images (at different magnifications) of FeSi@ PDA.
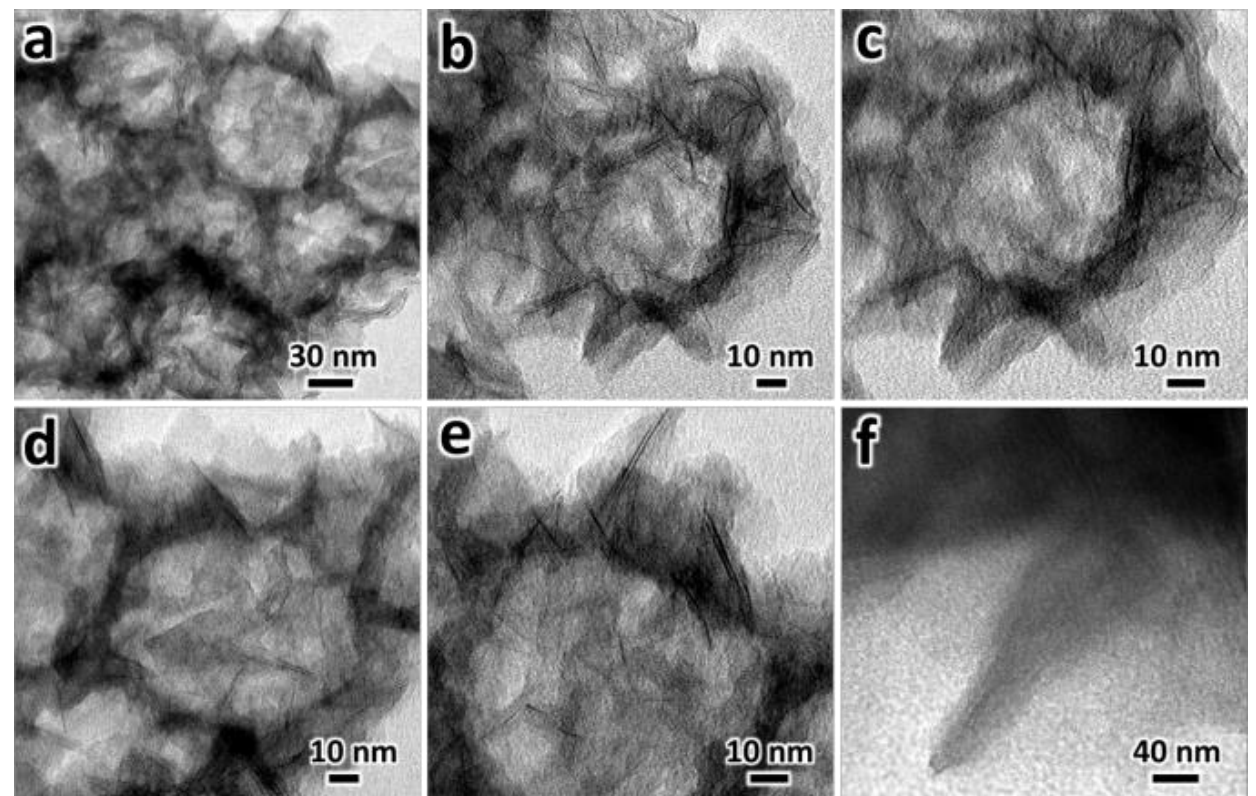

Figure S11. Representative TEM images (at different magnifications) of CoSi@PDA. 

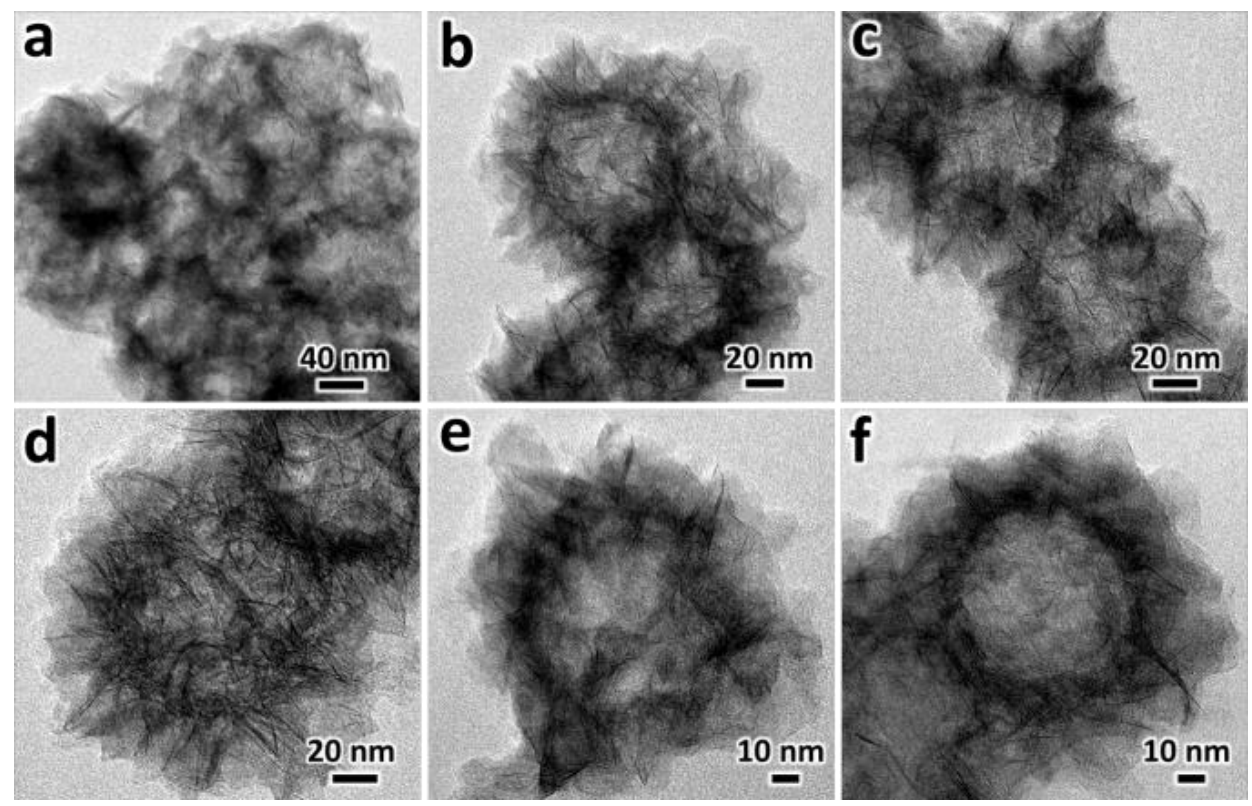

f

Figure S12. Representative TEM images (at different magnifications) of NiSi@PDA. 


\section{SI-5 XPS Characterization of TMSi@PDA}

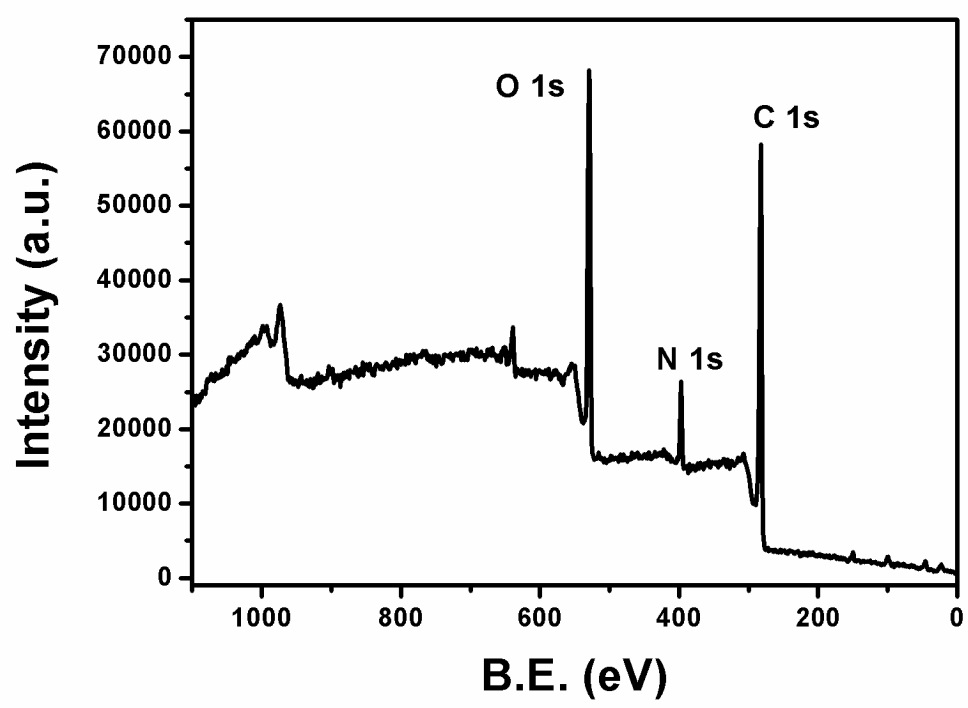

Figure S13. XPS spectrum with survey scan for MnSi@PDA sample.

Comments: No XPS signals belonging to Mn and Si elements were observed, which indicates that the Mn silicate core was fully covered by the PDA layer. 


\section{SI-6 Thermogravimetry Coupled with FTIR Characterization}

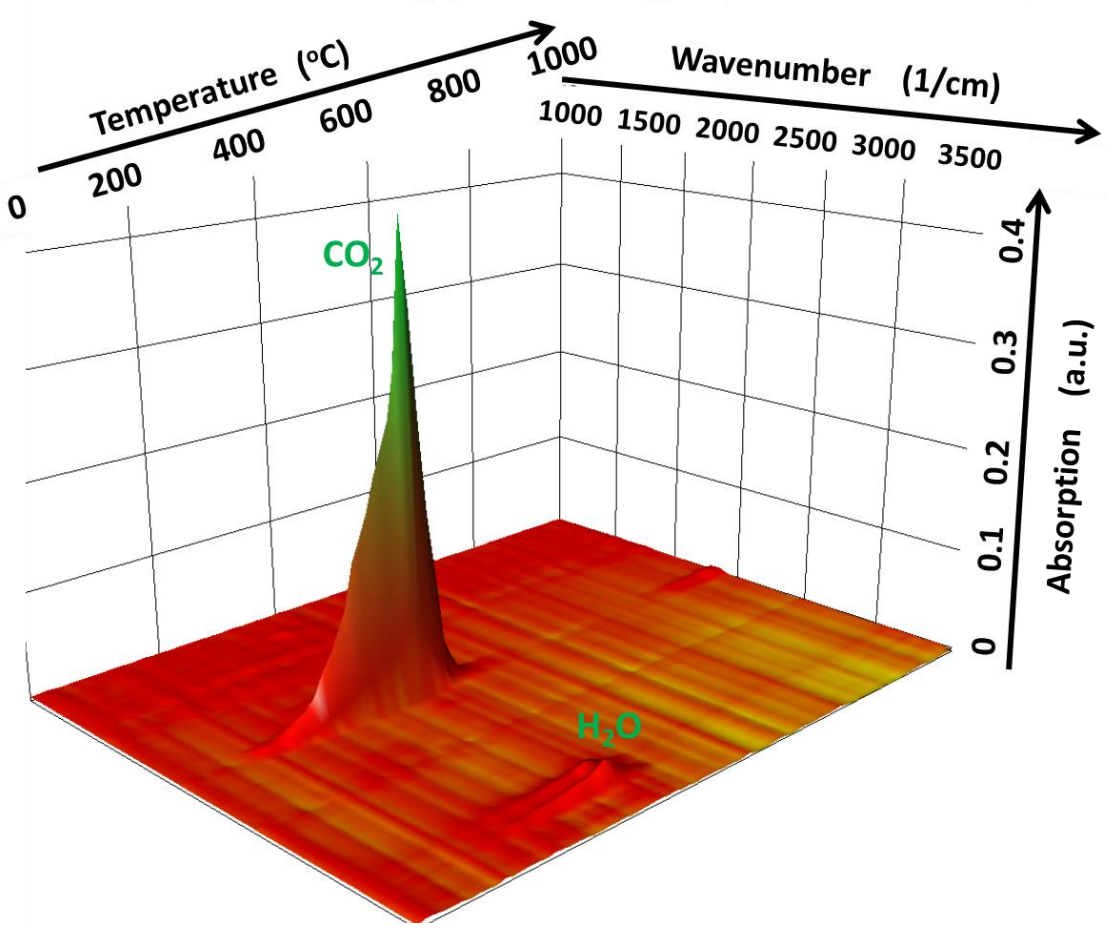

Figure S14. Profiled 3D-FTIR spectra of the evolved gases during the thermogravimetry analysis (TGA) of MnSi@PDA sample.

Comments: This figure is corresponding to Figure $7 \mathrm{~d}$ in the main text. As shown, the evolved gases include mainly water and $\mathrm{CO}_{2}$. However, we did not observe the evolved $\mathrm{NO}_{2}$ gas (or $\mathrm{N}$-containing gas) in the FTIR, probably due to a small amount of $\mathrm{N}$ element in PDA layer (i.e., below the detection limitation of the instrument). 


\section{SI-7 Characterization of Pt/TMSi (TM = Fe, Co, Ni)}

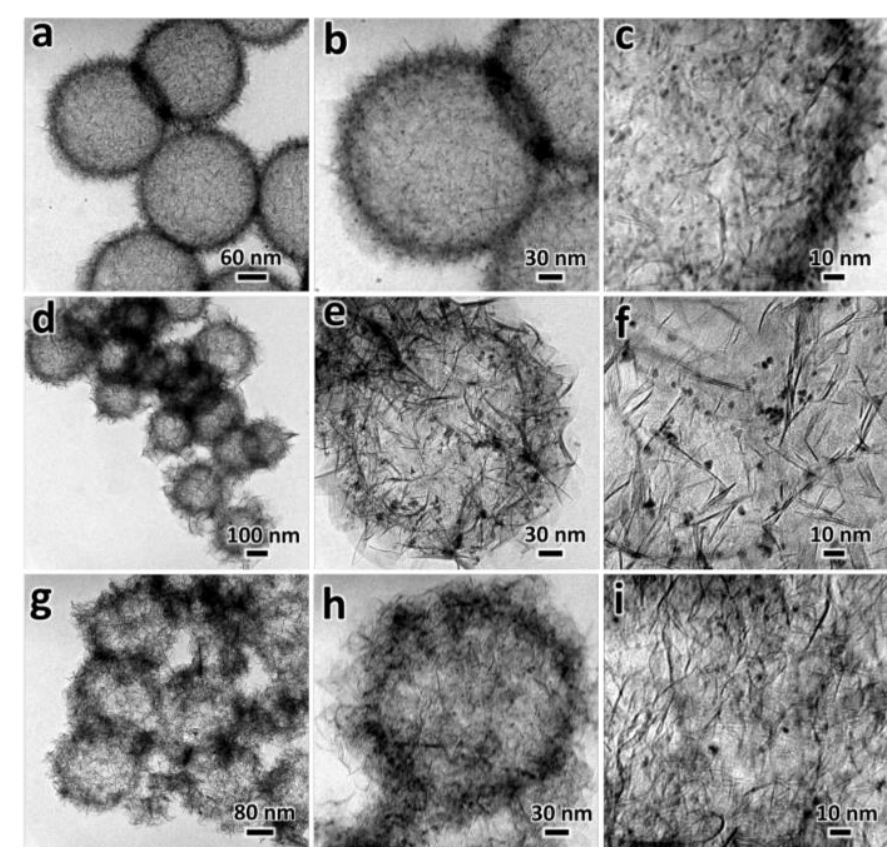

Figure S15. TEM images (at different magnifications) of (a-c) Pt/NiSi, (d-f) Pt/CoSi, and (g-i) $\mathrm{Pt} / \mathrm{FeSi}$ samples.

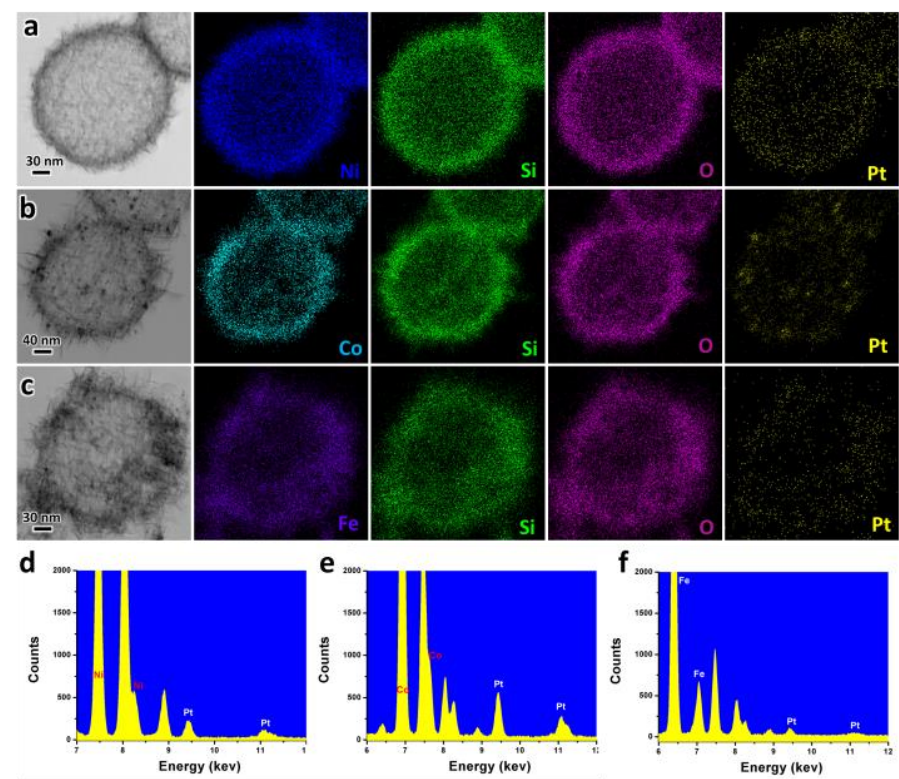

Figure S16. TEM images, EDX elemental maps, and the corresponding EDX spectra of $(a, d)$ $\mathrm{Pt} / \mathrm{NiSi}$, (b,e) $\mathrm{Pt} / \mathrm{CoSi}$, and (d,f) Pt/FeSi. Only peaks belonging to transition metals and $\mathrm{Pt}$ were labeled in the EDX spectra. 


\section{SI-8 Characterization of Pt/MnSi@PDA with Different PDA}

\section{Coating Thickness}
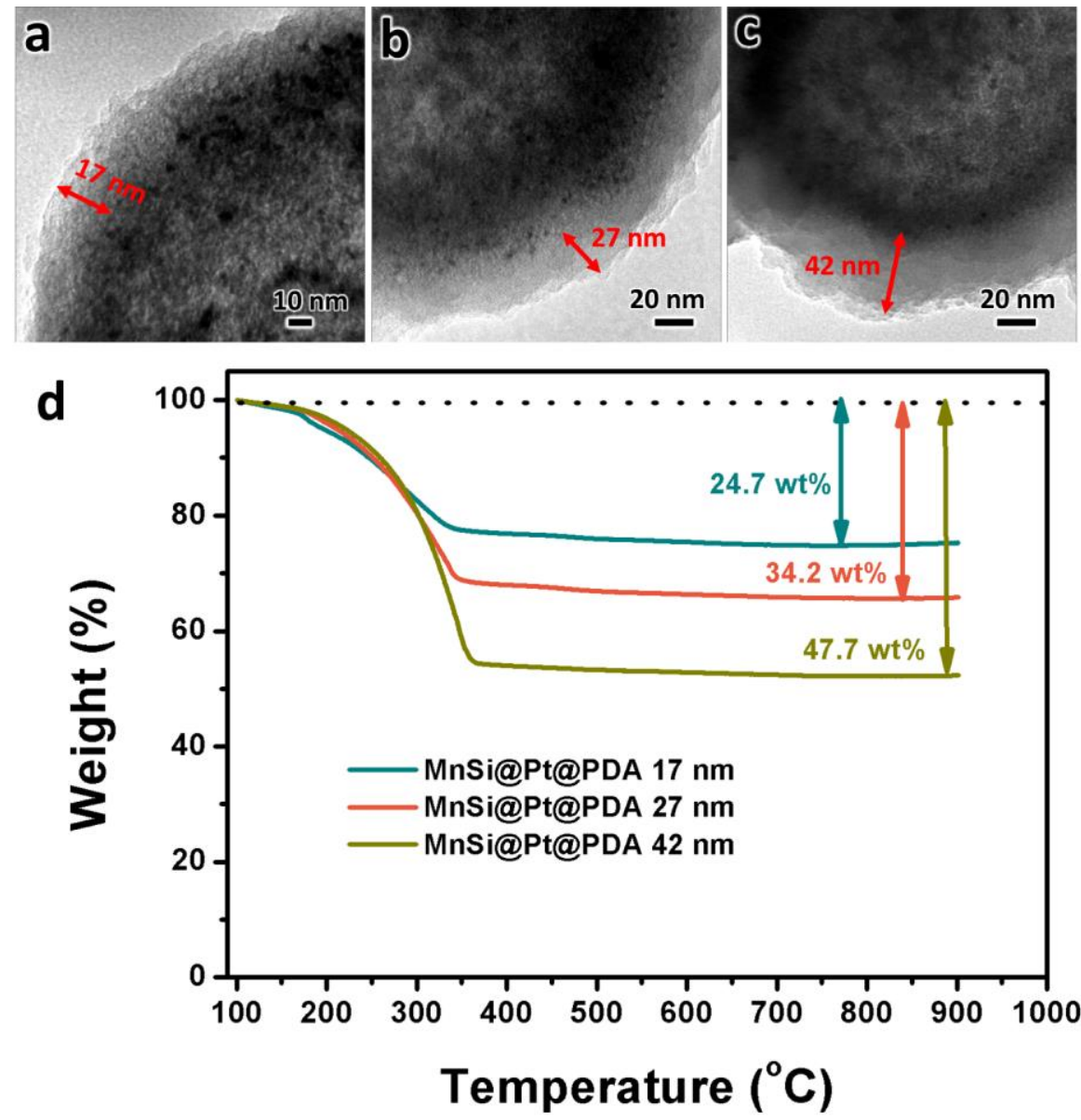

Figure S17. (a-c) TEM images and (d) TGA scans (in air atmosphere, $50 \mathrm{~mL} / \mathrm{min}$ ) of $\mathrm{Pt} / \mathrm{MnSi} @ \mathrm{PDA}$ samples with different thickness of PDA coating layer.

Comments: The thickness of PDA layer was adjusted by changing the amount of dopamine monomer in the synthetic solution as $5 \mathrm{mg}, 10 \mathrm{mg}$, and $20 \mathrm{mg}$, respectively. Accordingly, the thickness of PDA layer increases from $17 \mathrm{~nm}, 27 \mathrm{~nm}$, to $42 \mathrm{~nm}$. Moreover, the PDA contents in the three Pt/MnSi@PDA catalysts were measured as 24.7 wt $\%, 34.2$ wt $\%$, and 47.7 wt $\%$, respectively. In this work, the thickness of PDA layer was measured according to the corresponding TEM images of the samples. Average thicknesses were obtained based on at least 30 particles of each sample. 


\section{SI-9 XPS Characterization of Pt/TMSi@PDA}

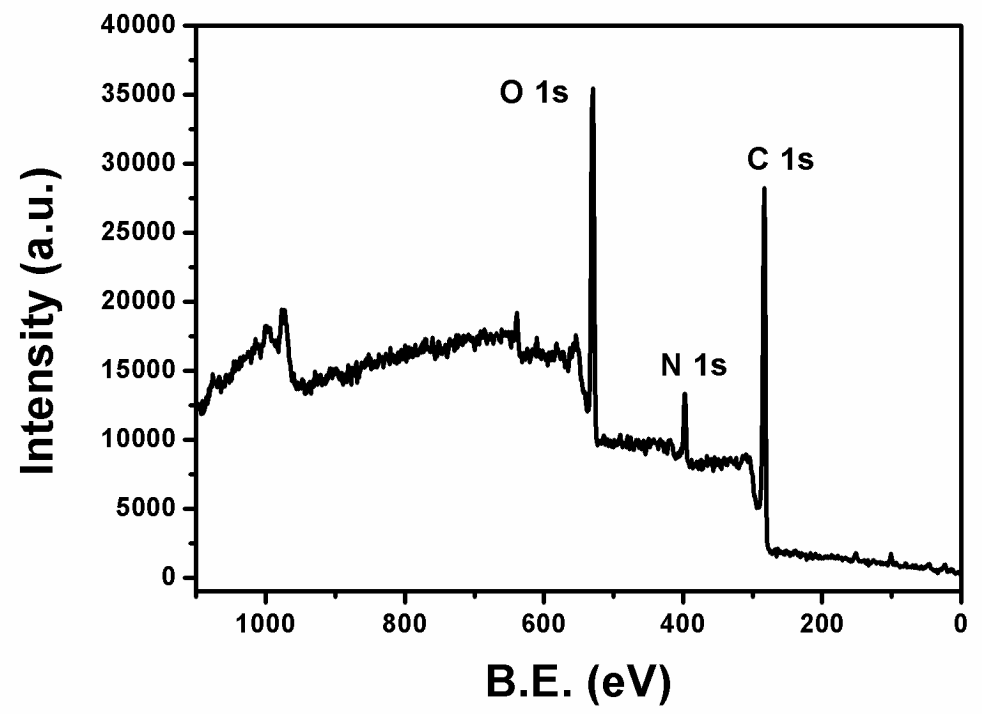

Figure S18. XPS spectrum with survey scan for Pt/MnSi@PDA sample.

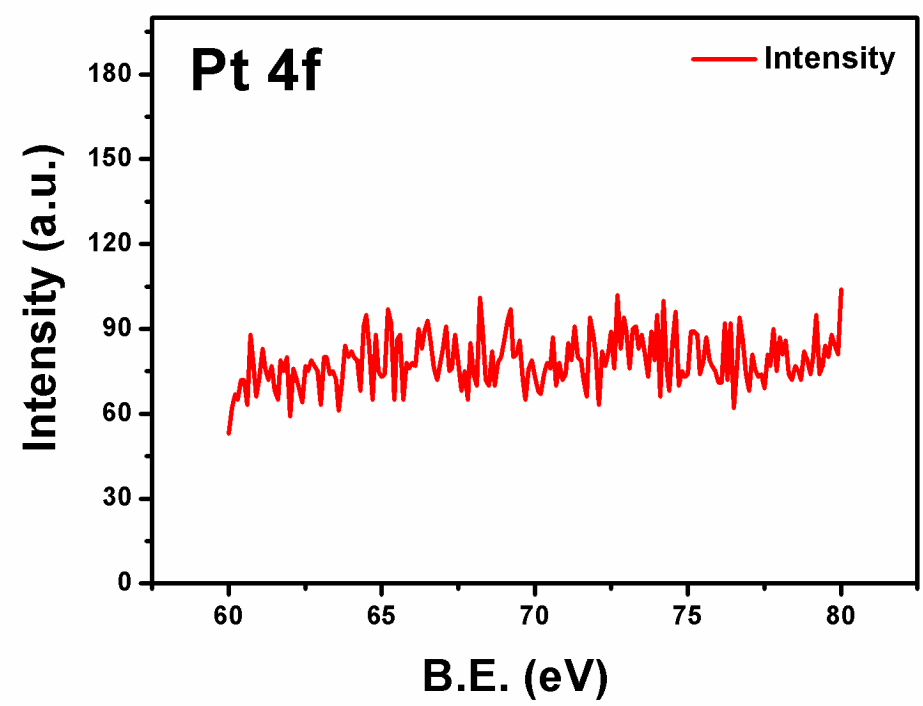

Figure S19. High resolution Pt $4 f$ core-level XPS spectrum of Pt/MnSi@PDA sample.

Comments: Since no XPS signal belonging to Pt was found in Pt/MnSi@PDA sample, it can be concluded that Pt nanoparticles were fully covered by the PDA shell. Therefore, Pt nanoparticles are sandwiched mostly between the PDA shell and MnSi core (see Figure 1 in the main text). 


\section{SI-10 Zeta-Potential of Pt/TMSi@PDA}

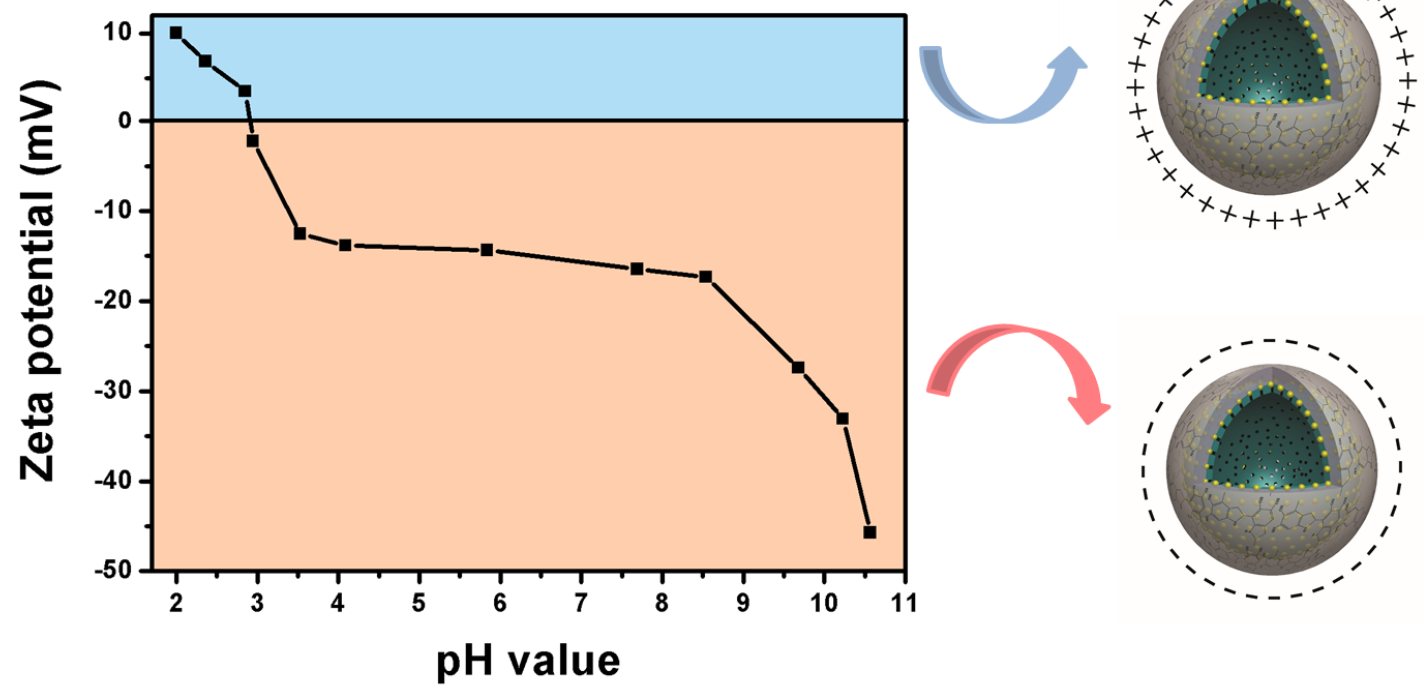

Figure S20. Plot of the zeta-potential of Pt/MnSi@PDA samples measured as a function of $\mathrm{pH}$ value. 


\section{SI-11 Characterization of Pt/TMSi@PDA (TM = Fe, Co, Ni)}

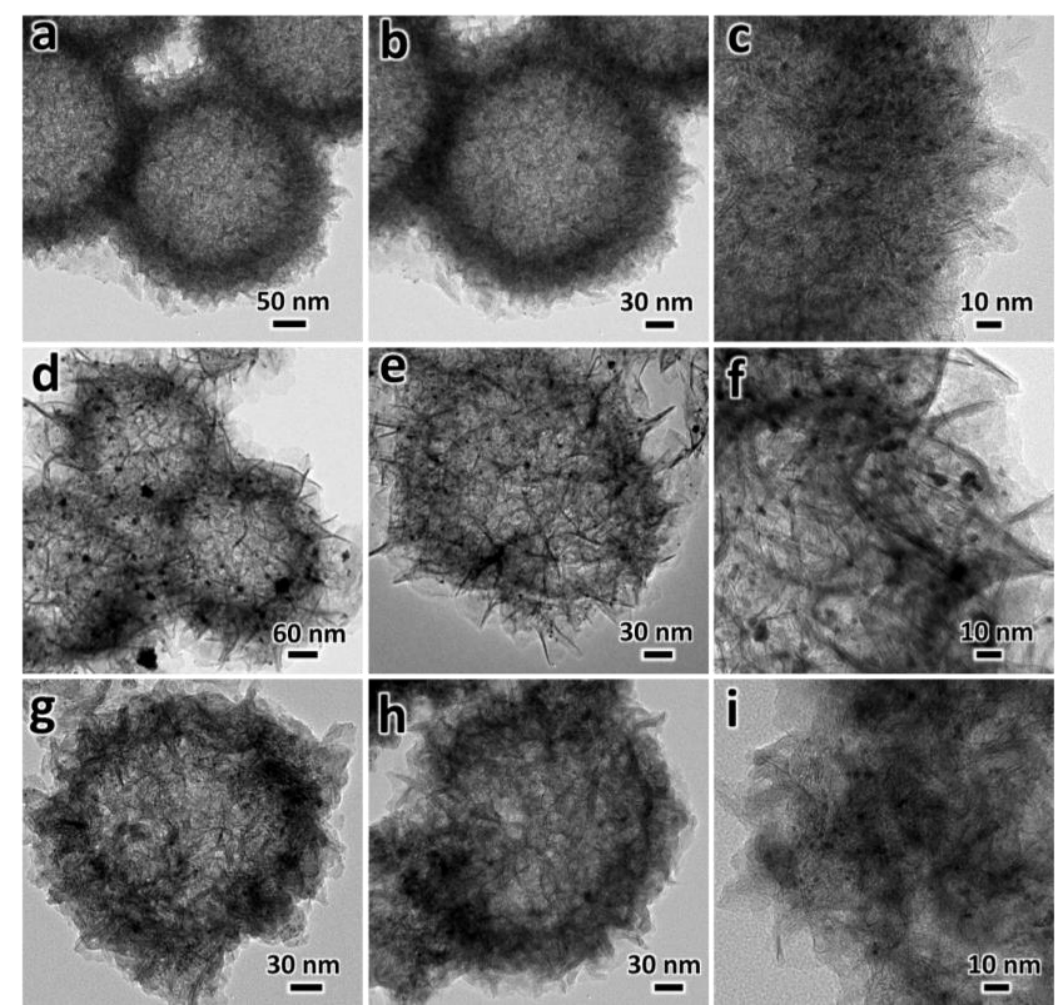

Figure S21. TEM images (at different magnifications) of (a-c) Pt/NiSi@PDA, (d-f)

Pt/CoSi@PDA, and (g-i)Pt/FeSi@PDA. The mass ratio between Pt/TMSi and dopamine in the synthetic solution was set at $2: 1(20 \mathrm{mg}$ to $10 \mathrm{mg})$. 


\section{SI-12 Organic Dyes Degradation}<smiles>CN(C)c1ccc2nc3cc/c(=[N+](/C)Cl)cc-3sc2c1</smiles>

Methylene blue<smiles>CCN=c1cc2oc3cc(NCC)c(C)cc3c(-c3ccccc3C(=O)OCC)c-2cc1C</smiles><smiles>Cc1cc(O)c(C(C)C)cc1C1=CC(=O)C(=O)C=C1c1ccccc1O</smiles>

$$
\text { Thymol blue }
$$

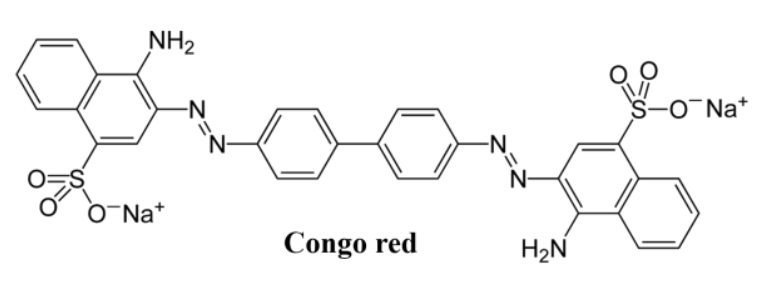$$
\text { Cong red }
$$

$$
\text { (1) }
$$<smiles>CN(C)c1ccc(/N=N/c2ccc(S(=O)(=O)O[NH3+])cc2)cc1</smiles>

Figure S22. Molecular structures of organic dyes studied in this work.
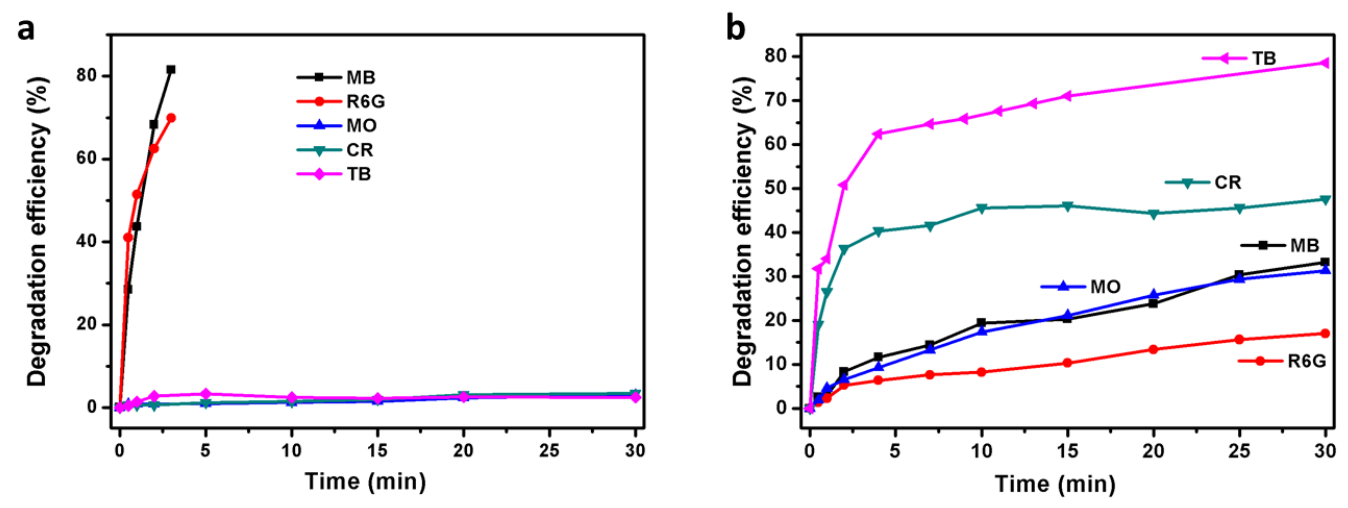

Figure S23. Degradation efficiency vs. time plots for five different dyes over Pt/MnSi@PDA catalyst at (a) pH of 10, and (b) pH of 2. Data was obtained from the time dependence UV-vis spectra profiles shown in main text (Figure 10 and Figure 11). 

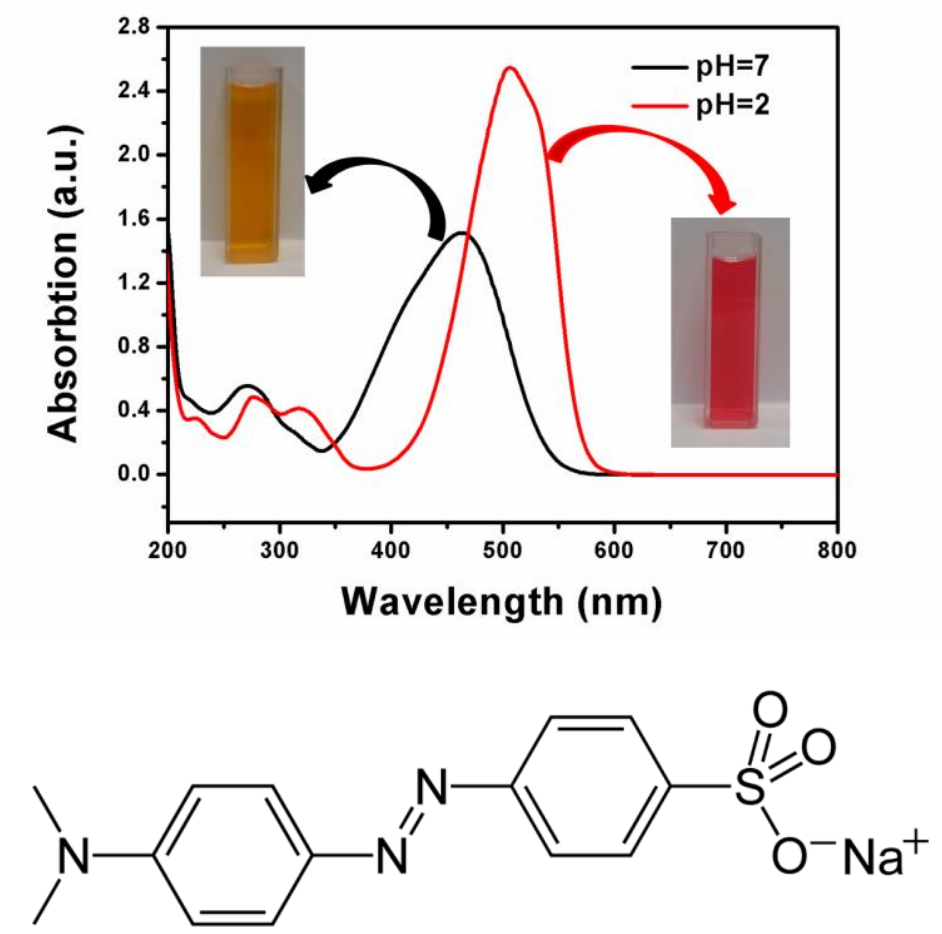

Figure S24. UV-vis spectra of methyl orange (MO) in different $\mathrm{pH}$ conditions.
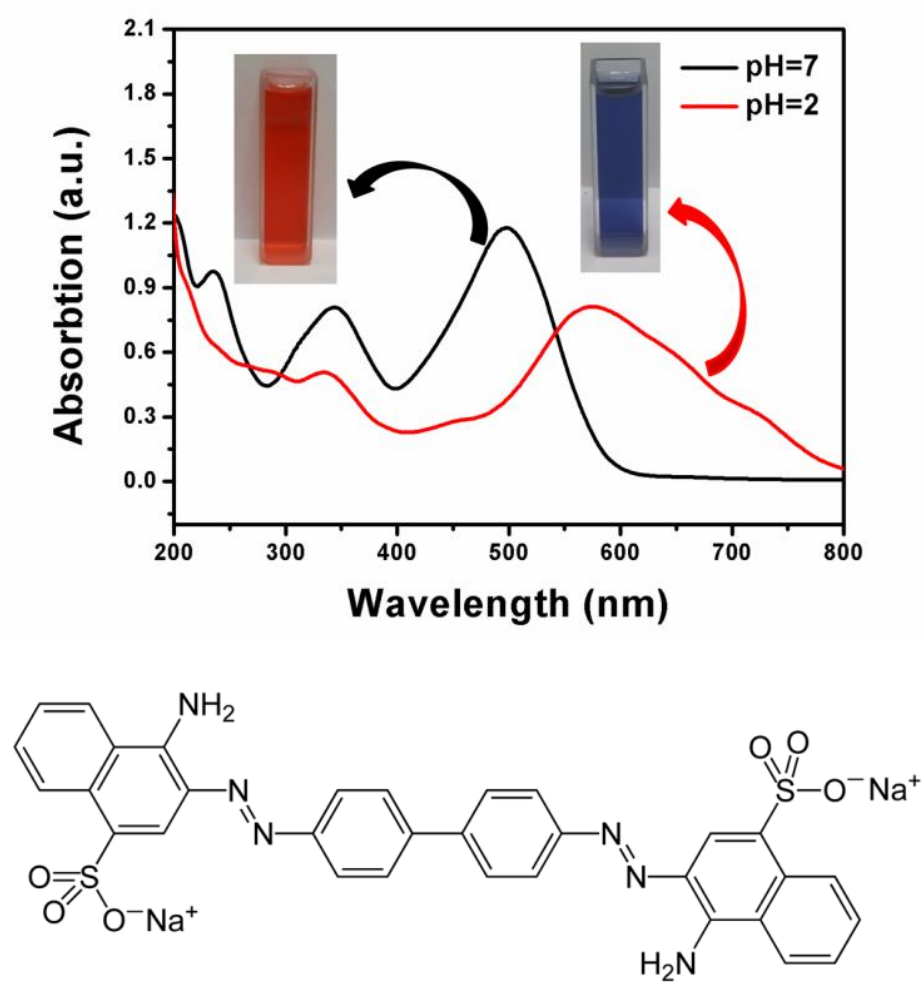

Figure S25. UV-vis spectra of Congo red (CR) in different $\mathrm{pH}$ conditions. 

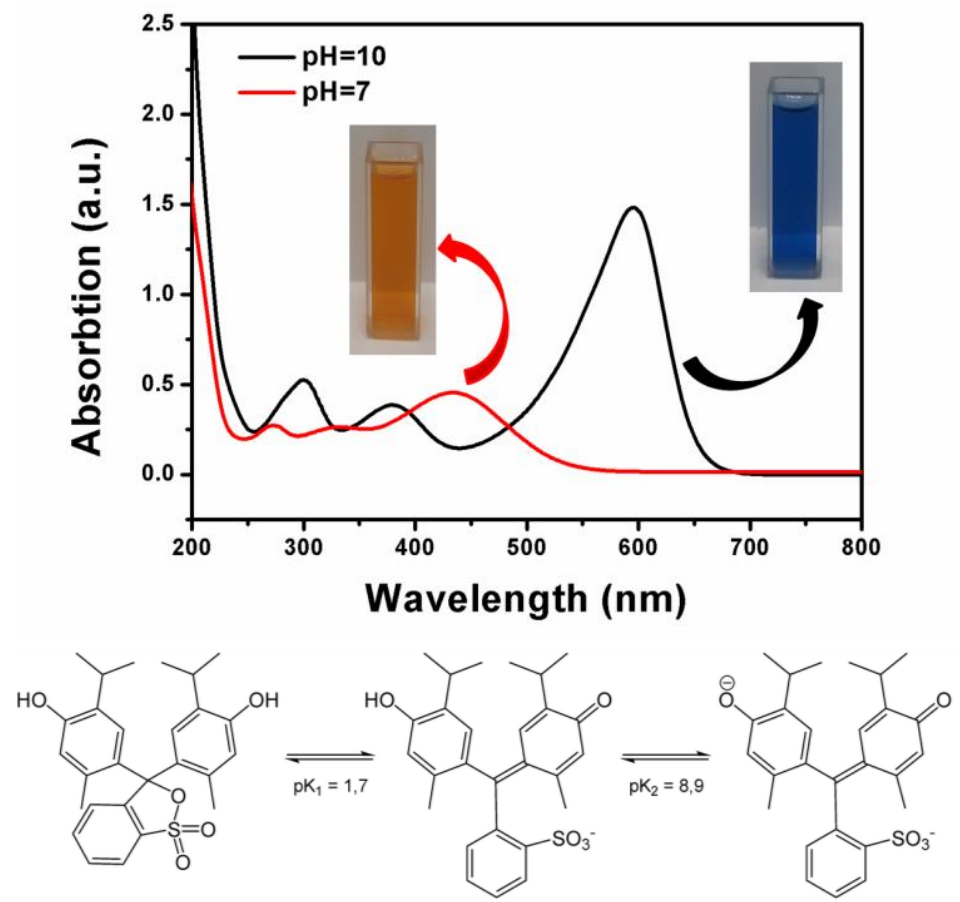

Figure S26. UV-vis spectra of thymol blue (TB) in different $\mathrm{pH}$ conditions.

Comments: The color of TB changes from yellow to blue when the $\mathrm{pH}$ value increases from 7 to 10. Due to that the reported $\mathrm{pK}_{1}$ value of TB is 1.7 in aqueous solution, $\mathrm{TB}$ molecules exist mainly in anionic state at both $\mathrm{pH}$ conditions of 2 and 10 (referring the molecule structure in Figure S26).

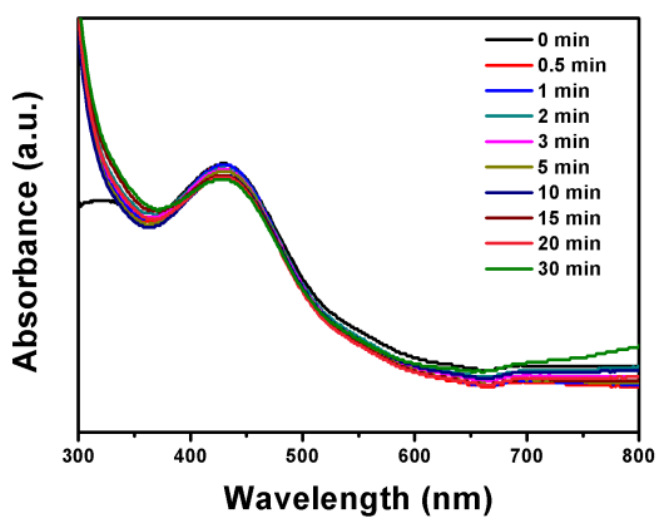

Figure S27. UV-vis absorption spectra of thymol blue (TB) as a function of time during the advanced oxidation processes (AOP) by using Mn silicate as a catalyst at solution $\mathrm{pH}$ of 2 . 


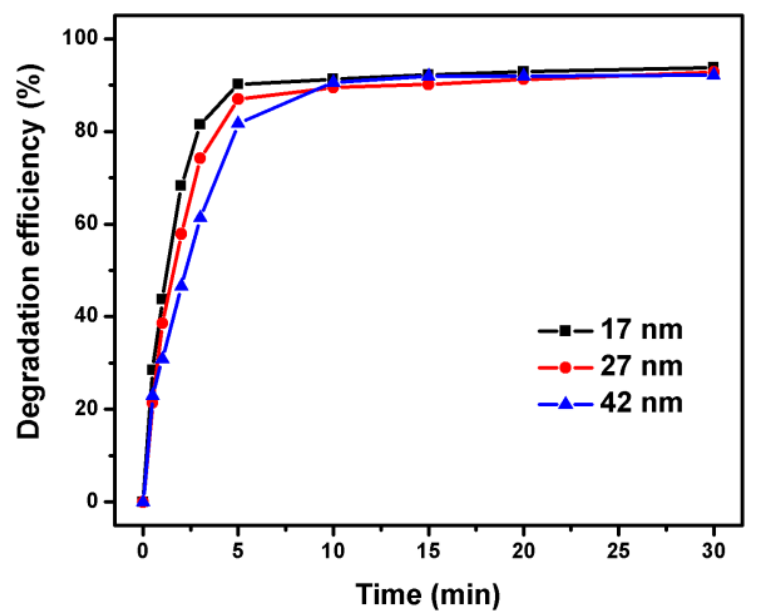

Figure S28. Degradation efficiency vs. time plots for MB over Pt/MnSi@PDA catalysts with different thickness of PDA coating layer (equal amount of Pt was used for different catalysts).
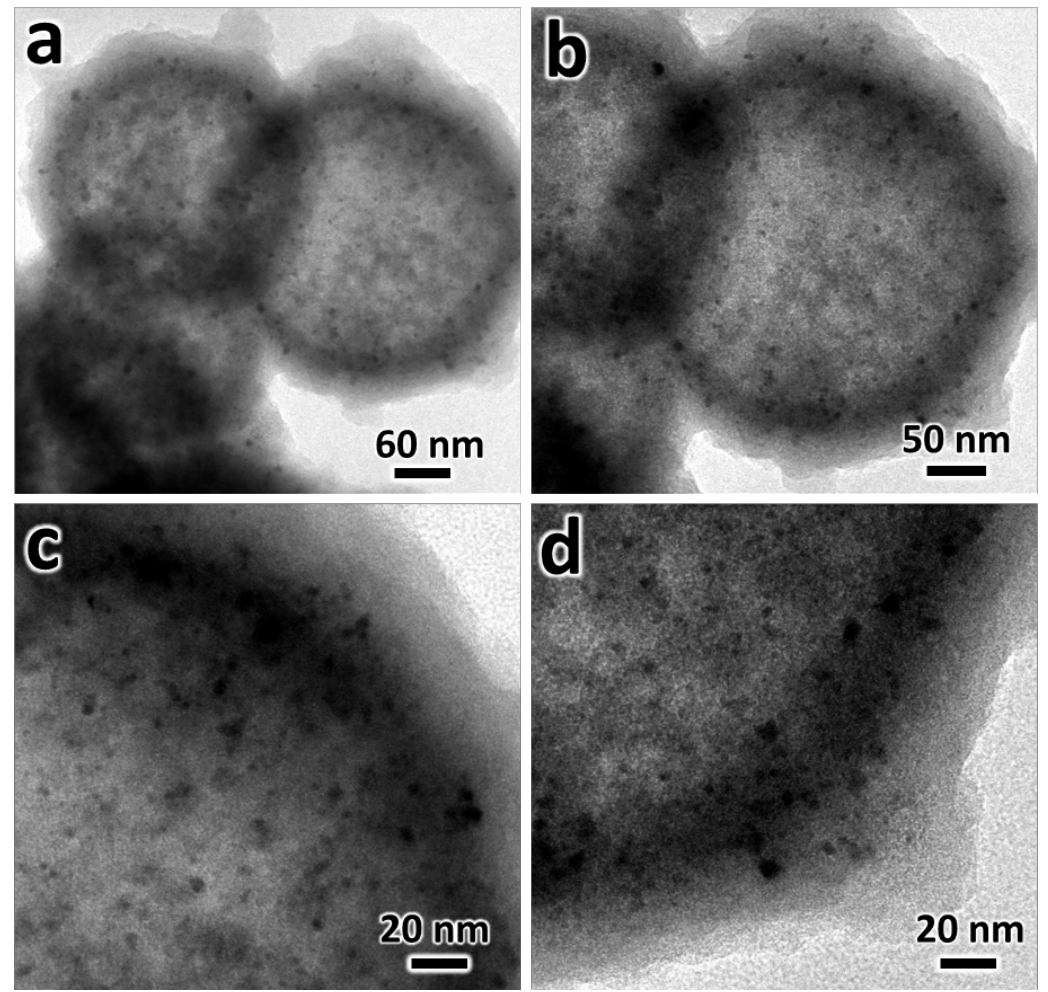

Figure S29. (a-d) Representative TEM images (at different magnifications) of Pt/MnSi@ NC catalyst. 


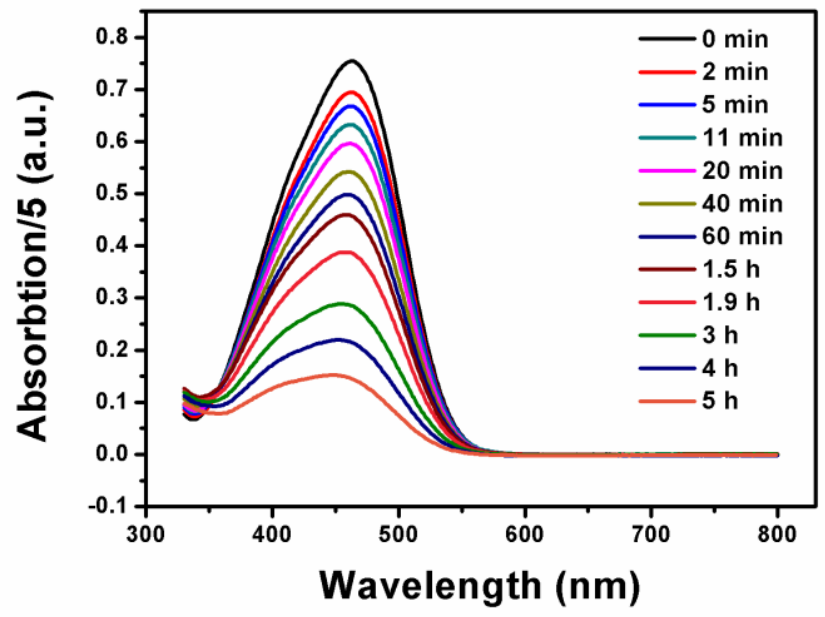

Figure S30. Degradation of MO in a control experiment by adding $5 \mathrm{~mL}$ of $\mathrm{H}_{2} \mathrm{O}_{2}$ in the absence of Pt/TMSi@PDA catalyst.

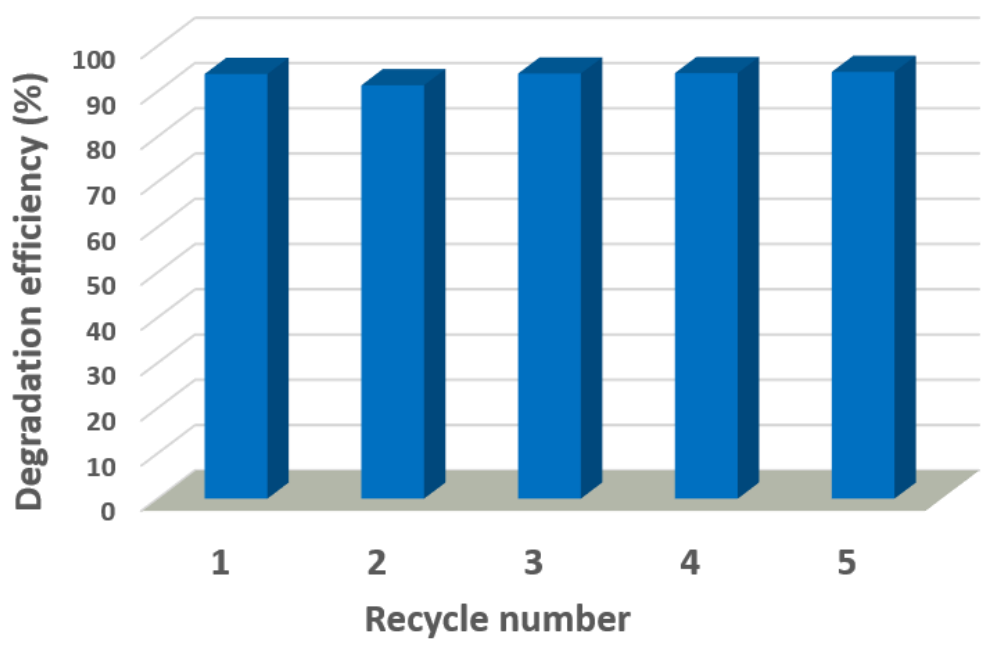

Figure S31. Catalyst stability of Pt/MnSi@PDA presented with degradation efficiency toward MB during five consecutive reactions ( $50 \mathrm{mg} / \mathrm{L}, \mathrm{pH}$ of 10 , and time of $30 \mathrm{~min}$ ). 

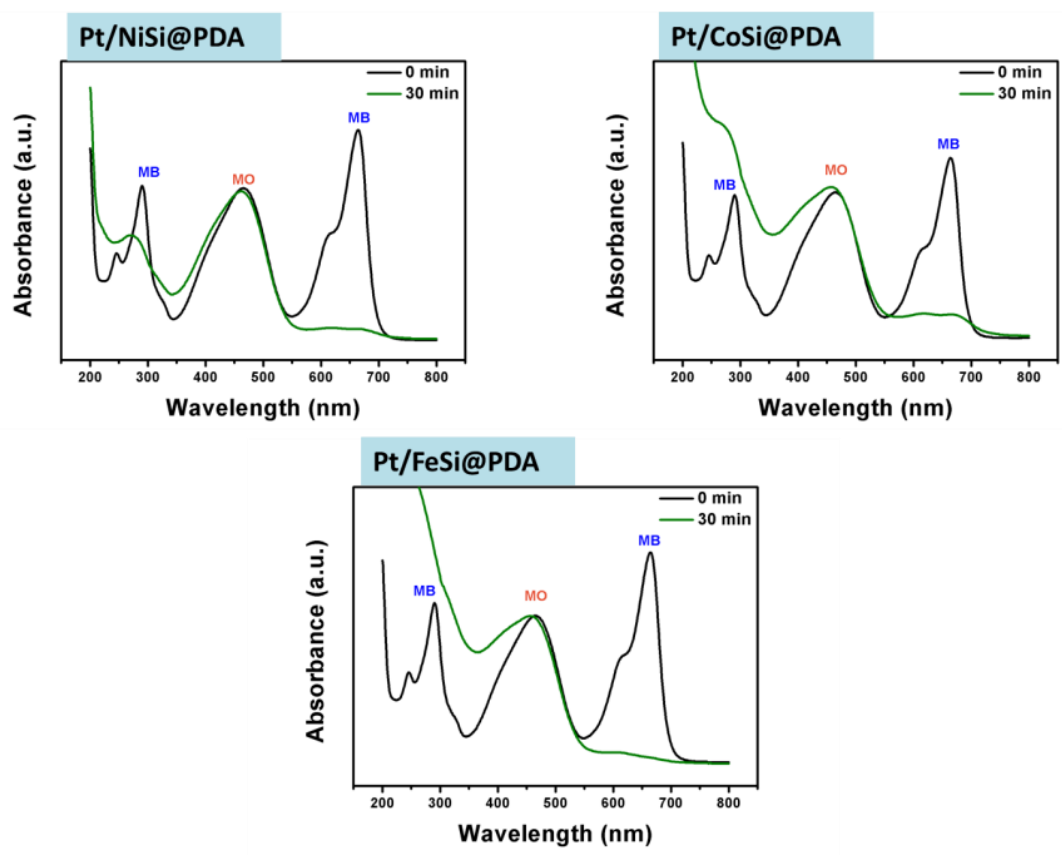

Figure S32. UV-vis absorption spectra of MO/MB mixtures during the advanced oxidation processes (AOP) over three different catalysts. Conditions: solution $\mathrm{pH}$ of 10, $\mathrm{MB}$ concentration of $50 \mathrm{mg} / \mathrm{L}$, and MO concentration of $25 \mathrm{mg} / \mathrm{L}$. The reactions finished at about $10 \mathrm{~min}$, and UV-vis absorption spectra of the solution at $10 \mathrm{~min}$ were quite similar to the ones at $30 \mathrm{~min}$.

\section{References}

(1) Groen, J. C.; Peffer, L. A. A.; Pérez-Ramírez, J. Pore Size Determination in Modified Micro- and Mesoporous Materials. Pitfalls and Limitations in Gas Adsorption Data Analysis. Microporous Mesoporous Mater. 2003, 60, 1-17.

(2) Ravikovitch, P. I.; Neimark, A. V. Experimental Confirmation of Different Mechanisms of Evaporation from Ink-Bottle Type Pores: Equilibrium, Pore Blocking, and Cavitation. Langmuir. 2002, 18, 9830-9837.

(3) Eggenhuisen, T. M.; Prieto, G.; Talsma, H.; de Jong, K. P.; de Jongh, P. E. Entrance Size Analysis of Silica Materials with Cagelike Pore Structure by Thermoporometry. J. Phys. Chem. C 2012, 116, 23383-23393. 